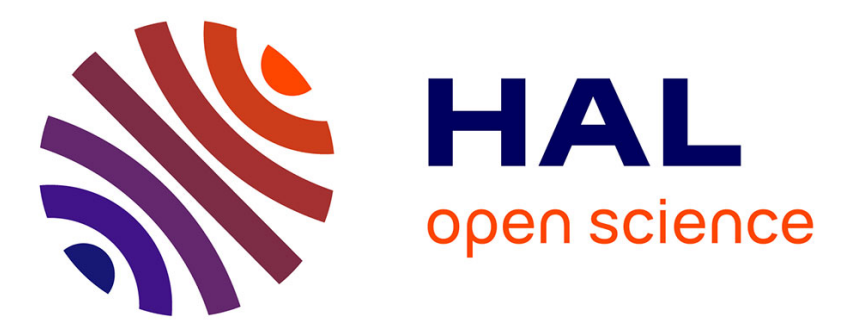

\title{
Physically-motivated elasto-visco-plastic model for the large strain-rate behavior of steels
}

Jean-Marc Pipard, Tudor Balan, Farid Abed-Meraim, Xavier Lemoine

\section{To cite this version:}

Jean-Marc Pipard, Tudor Balan, Farid Abed-Meraim, Xavier Lemoine. Physically-motivated elastovisco-plastic model for the large strain-rate behavior of steels. Key Engineering Materials, 2013, 554-557, pp.1164-1173. 10.4028/www.scientific.net/KEM.554-557.1164 . hal-01199757

\section{HAL Id: hal-01199757 \\ https://hal.science/hal-01199757}

Submitted on 16 Sep 2015

HAL is a multi-disciplinary open access archive for the deposit and dissemination of scientific research documents, whether they are published or not. The documents may come from teaching and research institutions in France or abroad, or from public or private research centers.
L'archive ouverte pluridisciplinaire HAL, est destinée au dépôt et à la diffusion de documents scientifiques de niveau recherche, publiés ou non, émanant des établissements d'enseignement et de recherche français ou étrangers, des laboratoires publics ou privés. 


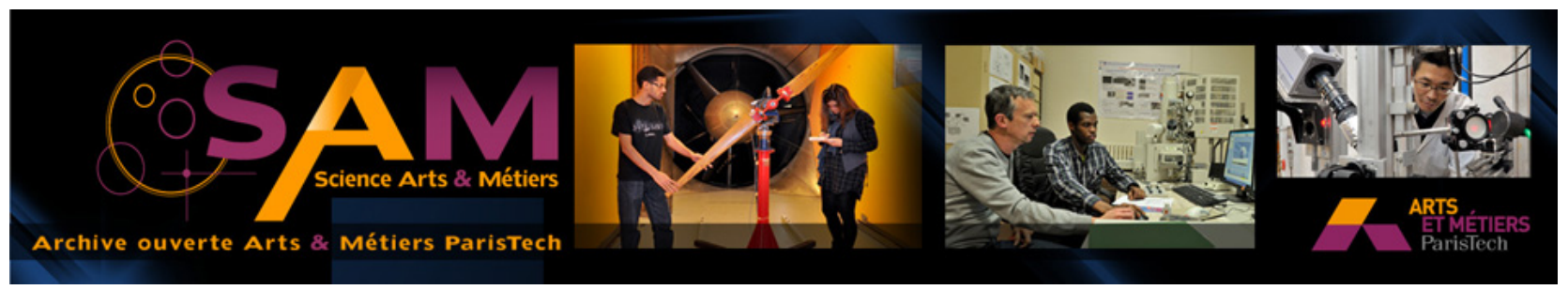

\section{Science Arts \& Métiers (SAM)}

is an open access repository that collects the work of Arts et Métiers ParisTech researchers and makes it freely available over the web where possible.

This is an author-deposited version published in: http://sam.ensam.eu

Handle ID: .http://hdl.handle.net/10985/10021

\section{To cite this version :}

Jean-Marc PIPARD, Tudor BALAN, Farid ABED-MERAIM, Xavier LEMOINE - Physicallymotivated elasto-visco-plastic model for the large strain-rate behavior of steels - Key Engineering Materials - Vol. 554-557, $n^{\circ}$ The Current State-of-the-Art on Material Forming, p.1164-1173 - 2013 


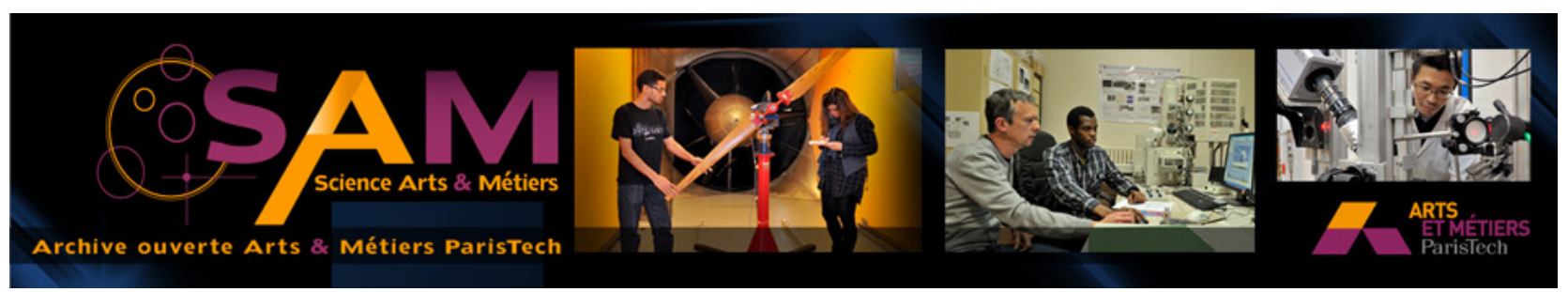

\section{Science Arts \& Métiers (SAM)}

is an open access repository that collects the work of Arts et Métiers ParisTech researchers and makes it freely available over the web where possible.

This is an author-deposited version published in: http://sam.ensam.eu

Handle ID: .http://hdl.handle.net/null

\section{To cite this version :}

Jean-Marc PIPARD, Tudor BALAN, Farid ABED-MERAIM, Xavier LEMOINE - Physicallymotivated elasto-visco-plastic model for the large strain-rate behavior of steels - Physicallymotivated elasto-visco-plastic model for the large strain-rate behavior of steels - Vol. 554-557, p.1164-1173 - 2013 


\title{
Physically-motivated elasto-visco-plastic model for the large strain-rate behavior of steels
}

\author{
Jean-Marc Pipard ${ }^{1,2, a}$, Tudor Balan ${ }^{1, b}$, Farid Abed-Meraim ${ }^{1, \mathrm{c}}$, \\ Xavier Lemoine ${ }^{1,2, d}$
}

${ }^{1}$ Laboratoire d'Étude des Microstructures et de Mécanique des Matériaux, LEM3, UMR CNRS 7239, Arts et Métiers ParisTech, 4 rue Augustin Fresnel, 57078 Metz Cedex 03, France

\author{
${ }^{2}$ ArcelorMittal R\&D Global Maizières, Automotive Product, Voie Romaine, BP 30320, 57283 \\ Maizières-Lès-Metz Cedex, France

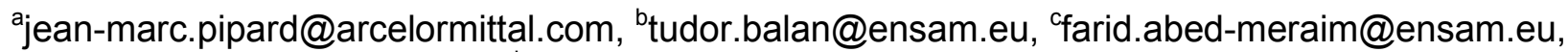 \\ dxavier.lemoine@arcelormittal.com
}

\begin{abstract}
Keywords: Constitutive behavior; Visco-plasticity; Microstructure-related parameters; Mild steel; Multiphase steel; Finite element simulation.
\end{abstract}

\begin{abstract}
A physically based elasto-visco-plastic constitutive model is presented and compared to experimental results for a DD14 mild steel. The model requires significantly fewer material parameters compared to other visco-plasticity models from the literature while exhibiting very good accuracy. Accordingly, the parameter identification is simple and intuitive, requiring a relatively small set of experiments. The strain-rate sensitivity modeling is not restricted to a particular hardening law and thus provides a general framework in which advanced hardening equations can be adopted and compared. The model has been implemented in the commercial finite element code Abaqus/Explicit. First predictions compared to experiments are analyzed and underline the effect of hardening law and strain-rate sensitivity on 3D finite element simulations. The model has been also applied as the basis for a homogenization approach at the phase scale; preliminary investigations showed the benefits of coupling such an approach with scale-transition technique where microstructure-relevant data can explicitly enter the model and may be used for material design simulations.
\end{abstract}

\section{Introduction}

Main industrial processes such as rolling, stamping or metal forming involve large deformations under non quasi-static loading conditions and frequent strain-path changes. In such circumstances, accurate description of the material behavior relies on the ability of the model to capture physical phenomena such as strain-rate sensitivity. This paper presents a physically-motivated elasto-viscoplastic model suitable to take into account main features of elasto-visco-plasticity such as strain-rate and temperature sensitivity. In its original form [1], the physically-based model is derived from the coupling between the Edgar Rauch's formalism [2] and a phenomenological physically-based constitutive elasto-visco-plastic law. In this paper, a tensorial approach, not restricted to any hardening law, is proposed for 3D finite element simulations of metal forming processes. A first basic $3 \mathrm{D}$ simulation of a tensile test is analyzed and compared to experiments. Then, within the framework of a homogenization approach, the complete formulation is used at the phase scale. Preliminary investigations on a V-bending simulation show the possible benefits of downgrading the scale of description.

\section{Formulation of the elasto-visco-plastic constitutive model}

Elasto-visco-plastic formulation for large deformations. Frame invariance of the material is ensured by reformulating constitutive equations in terms of rotation-compensated variables. Tensor quantities are written in a convenient rotating frame in which simple material time derivatives can be used in the constitutive equations. Therefore, the strain rate tensor $\dot{\boldsymbol{\varepsilon}}$ can be simply decomposed into an elastic part $\dot{\boldsymbol{\varepsilon}}^{e}$ and a visco-plastic part $\dot{\boldsymbol{\varepsilon}}^{v p}$. The elastic behavior is thus expressed as: 


$$
\dot{\boldsymbol{\sigma}}=\mathbf{C}:\left(\dot{\boldsymbol{\varepsilon}}-\dot{\boldsymbol{\varepsilon}}^{v p}\right) \text {. }
$$

where $\dot{\boldsymbol{\sigma}}$ is the Cauchy stress rate tensor and $\mathbf{C}$ the fourth-order elasticity tensor. The flow rule is defined by:

$$
\dot{\boldsymbol{\varepsilon}}^{v p}=\dot{\varepsilon}_{e q}^{v p} \mathbf{V} \quad, \quad \mathbf{V}=\frac{\partial \sigma_{e q}}{\partial \boldsymbol{\sigma}}=\frac{3}{2} \frac{\left(\boldsymbol{\sigma}^{\prime}-\mathbf{X}\right)}{\sigma_{e q}}
$$

where $\sigma_{e q}=\sqrt{\frac{3}{2}\left(\boldsymbol{\sigma}^{\prime}-\mathbf{X}\right):\left(\boldsymbol{\sigma}^{\prime}-\mathbf{X}\right)}$ is for the sake of simplicity the von Mises equivalent stress, $\boldsymbol{\sigma}^{\prime}$ denotes the deviatoric part of the Cauchy stress tensor and $\mathbf{X}$ the backstress variable, for kinematic hardening description. Obviously, any other yield function can be used without restriction.

Flow stress and flow rule adopted for BCC materials. The flow stress is the stress required to move the mobile dislocations according to the elastic fields generated by the different obstacles in the microstructure. Generally considered as the sum of three independent contributions for FCC materials, the flow stress for BCC materials is described in Rauch formalism as [2]:

$$
\sigma=\sigma_{0}+\frac{\sigma^{*}}{2}+\sqrt{R^{2}+\left(\frac{\sigma^{*}}{2}\right)^{2}} .
$$

where $\sigma^{*}$ is the effective stress required for the mobile dislocations to overcome the local obstacles with the help of thermal fluctuations, $\sigma_{0}$ the initial athermal flow stress depending of the alloying elements and $\mathrm{R}$ the long range internal stress due to microstructure obstacles. The Rauch formalism, based on energetic considerations, implies a coupling between the effective thermal activated stress $\sigma^{*}$ and $\mathrm{R}$.

$$
\sigma_{e q}-\left(\sigma_{0}+\frac{\sigma^{*}}{2}\right)-\sqrt{R^{2}+\left(\frac{\sigma^{*}}{2}\right)^{2}} \leq 0 .
$$

The relationship between the scalar overstress $\sigma^{*}$ and the equivalent visco-plastic strain-rate $\dot{\varepsilon}_{e q}^{v p}$ is expressed by the following relationship [1]:

$$
\sigma^{*}=K^{*} \sinh ^{-1}\left(\frac{\dot{\varepsilon}_{e q}^{p p}}{\dot{\varepsilon}^{*}}\right) .
$$

where $K^{*}$ and $\dot{\varepsilon}^{*}$ are material parameters. The strain-rate sensitivity affects both the initial yield stress and the hardening term because of the coupling used in the Rauch formalism (Eq. 3). It is worth noting that any isotropic hardening model can be adopted. In this paper, a six-parameter law is used, corresponding to a linear combination between Voce and Swift hardening laws:

$$
\dot{R}=\alpha \dot{R}^{V}+(1-\alpha) \dot{R}^{S} \text {. }
$$

where $\dot{R}^{V}=C_{R}\left(R_{s a t}-R\right) \dot{\varepsilon}_{e q}^{v p}$ and $\dot{R}^{S}=n K^{\frac{1}{n}}\left(K \varepsilon_{0}^{n}+R\right)^{\frac{n-1}{n}} \dot{\varepsilon}_{e q}^{v p}$ are respectively the Voce and Swift hardening formulations. $C_{R}, R_{\text {sat }}, K, n, \varepsilon_{0}$, and $\alpha$ are material parameters. For the sake of simplicity, kinematic hardening represented by the backstress tensor $\mathrm{X}$ is described by the nonlinear model of Armstrong-Frederick:

$$
\dot{\mathbf{X}}=C_{X}\left(X_{s a t} \mathbf{N}-\mathbf{X}\right) \dot{\varepsilon}_{e q}^{v p} \quad, \quad \mathbf{N}=\frac{\mathbf{V}}{\|\mathbf{V}\|} .
$$

where $C_{X}$ et $X_{\text {sat }}$ are material parameters. 


\section{Experimental validations and application}

Parameter identification and comparison with experiments. The proposed constitutive model has been previously applied to three different mild steels and compared to tensile tests performed at different strain rates, quasi-static reverse shear tests and two-step sequential loadings [3]. Results showed the ability of the model to capture the main features of elasto-visco-plasticity: the increase of the tensile flow stress with strain rate is well predicted. Description of the temperature sensitivity of the mean flow stress is also claimed by adding two fitting parameters. Figure 1 illustrates the capability of the model to capture strain-rate sensitivity: tensile tests at four different strain rates are compared with model predictions for a DC05 steel sheet. Identification of material parameters, simple and intuitive, is given on Table 1. Despite the small number of parameters that require identification, the model showed similar ability to reproduce the main features of elasto-viscoplasticity of mild steels when compared to other physically-motivated models from the literature $[4,5]$.

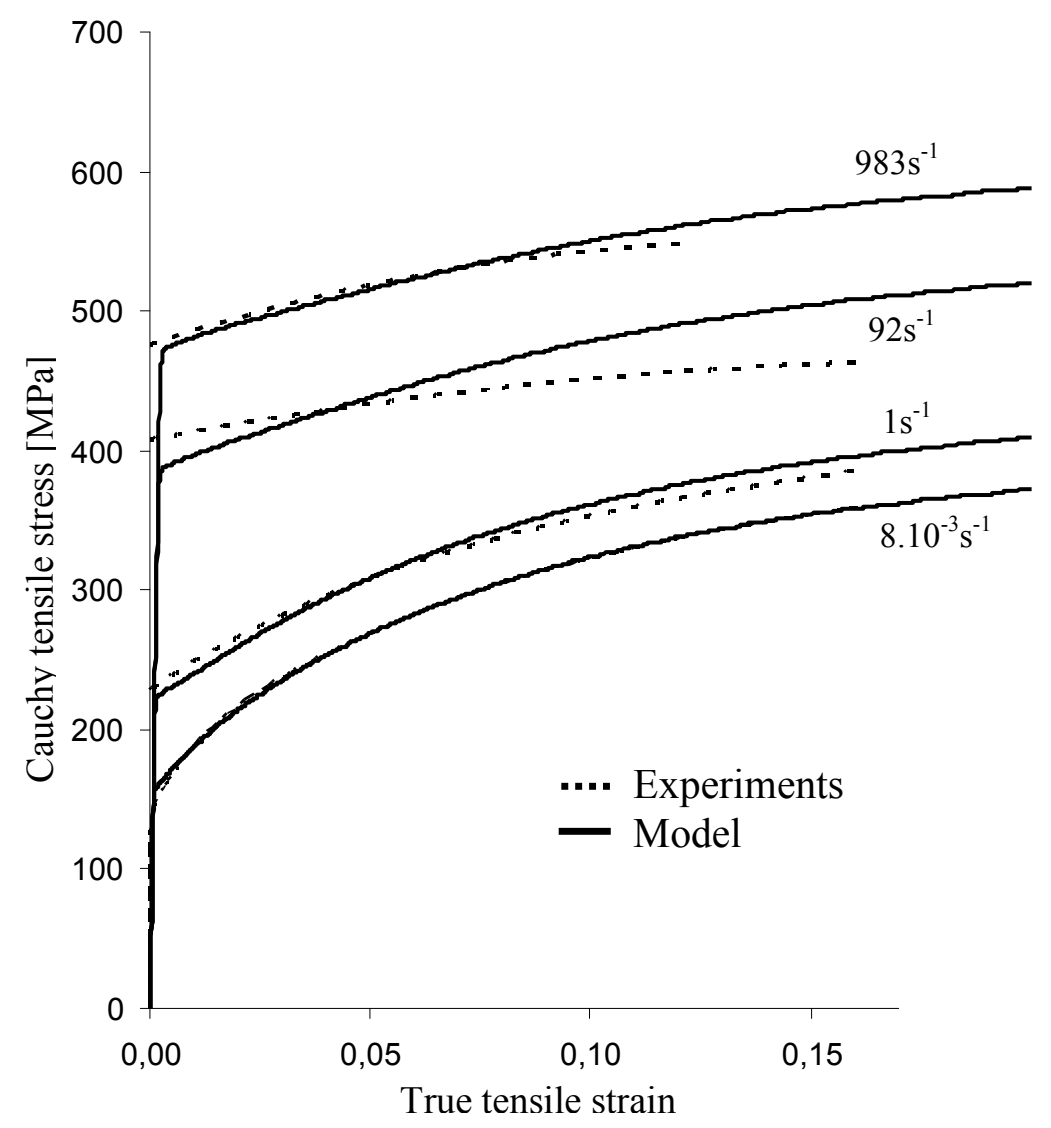

Figure 1. Comparison between experiments (dashed lines) and model predictions (solid lines) for a DC05 steel sheet under monotonic tensile tests (strain-rate sensitivity effect).

Table 1. Material parameters for the DC05 mild steel.

\begin{tabular}{ccccccccc}
\hline$\sigma_{0}[\mathrm{MPa}]$ & $C_{R}$ & $R_{\text {sat }}[\mathrm{MPa}]$ & $K[\mathrm{MPa}]$ & $\varepsilon_{0}$ & $n$ & $\alpha$ & $K^{*}[\mathrm{MPa}]$ & $\dot{\varepsilon}^{*}\left[\mathrm{~s}^{-1}\right]$ \\
\hline 155 & 13 & 200 & - & - & - & 1 (Voce) & 36 & 0.3 \\
\hline
\end{tabular}


Simulation of post-necking tensile response. The constitutive model has been implemented in the commercial finite element code Abaqus/Explicit using an explicit time-integration scheme [6] to allow for the simulation of sheet metal forming and crash experiments. Lemoine and co-workers $[7,8,9]$ compared different non-saturating and saturating classical isotropic hardening models. The models have been identified on standard tests and then confronted to experiments allowing larger plastic strain levels. This comparison for a wide range of steel grades revealed that large plastic strains are better described with an isotropic hardening model combining Swift and Voce laws. In the present paper, the proposed constitutive model has been applied to a finite element simulation of a tensile test in order to highlight the benefits of taking account of the strain-rate sensitivity and the effect of choices of the isotropic hardening law. To simplify the analysis, kinematic hardening has not been taken into account in this part. Three simulations have been analyzed and differ by the content of the constitutive model used in terms of strain-rate sensitivity and by the type of hardening description:

- A strain-rate insensitive model using the isotropic hardening law of Voce, this model will be called "Voce quasi-static" in the following;

- A strain-rate insensitive model using an isotropic hardening model combining the Swift and Voce laws, called "S-V quasi-static";

- The proposed elasto-visco-plastic model, using the same hardening equations and parameters as the "S-V quasi-static" model, called "S-V visco-plastic".

The identified parameters are given in Table 2 and have been obtained according to [3] on a hot rolled DD14 mild steel. Figure 2a shows the comparison between model predictions and experiments for a quasi-static uniaxial tensile test. Similar behavior is depicted at low strain rates where homogeneous deformation in quasi-static conditions cannot differentiate strain-rate sensitive models from insensitive models. Differences between the hardening models become noticeable as soon as larger strains are experienced by the specimen. Beyond the homogeneous strain domain, the experimental true-stress-true-strain curve is not available and the extrapolation of the curve beyond this uniform strain state is not straightforward and will impact finite element simulations at larger strains.

Table 2. Material parameters for the 3-mm-thick DD14 mild steel.

\begin{tabular}{ccccccccc}
\hline$\sigma_{0}[\mathrm{MPa}]$ & $C_{R}$ & $R_{\text {sat }}[\mathrm{MPa}]$ & $K[\mathrm{MPa}]$ & $\varepsilon_{0}$ & $n$ & $\alpha$ & $K^{*}[\mathrm{MPa}]$ & $\dot{\varepsilon}^{*}\left[\mathrm{~s}^{-1}\right]$ \\
\hline 259 & 12 & 147 & 543 & 0.02 & 0.193 & $\begin{array}{c}1(\mathrm{Voce}) \\
0.1(\mathrm{~S}-\mathrm{V})\end{array}$ & 56.92 & 0.3 \\
\hline
\end{tabular}



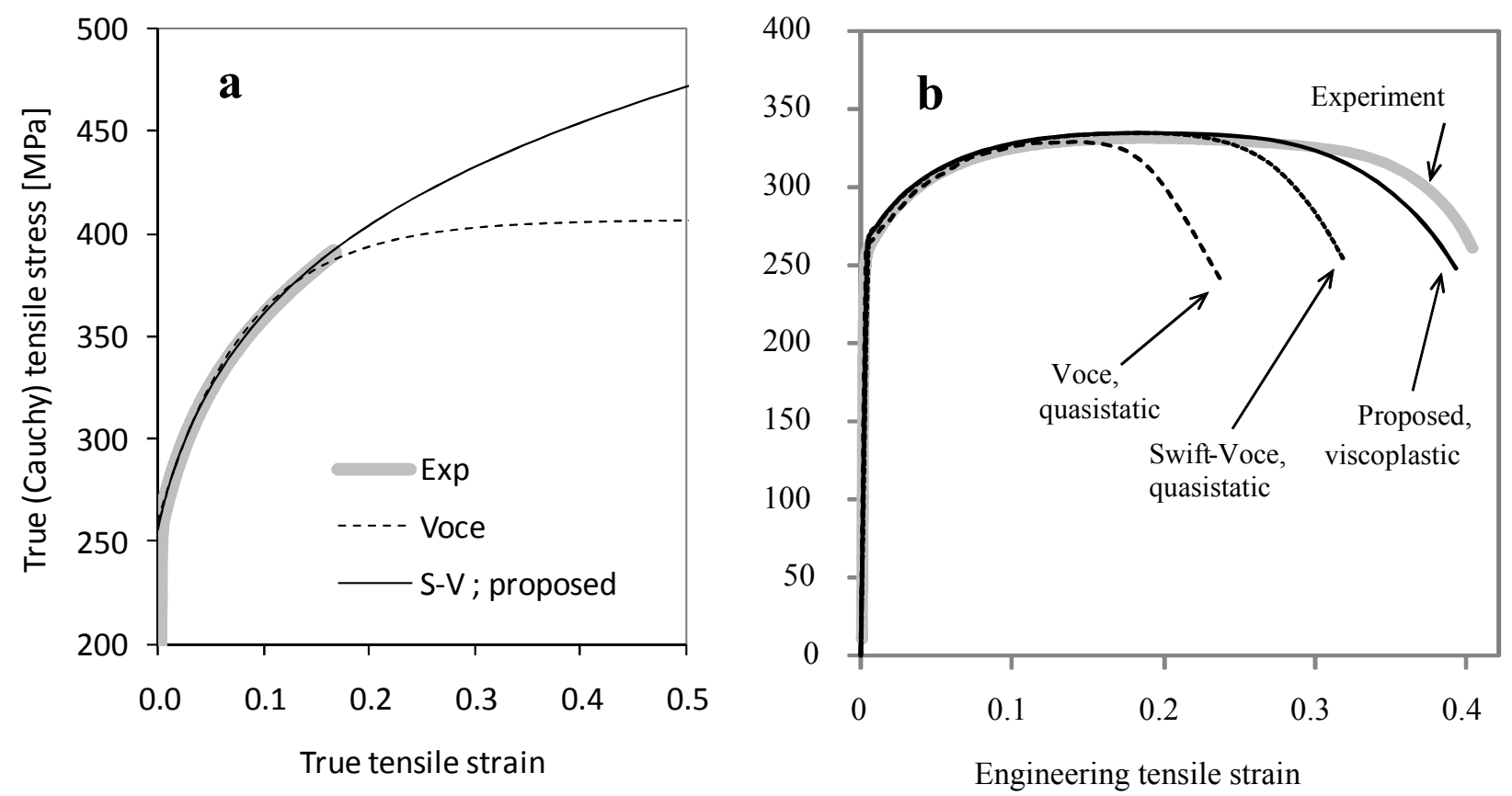

Figure 2. Comparison between model and simulation predictions and experiments on a hot rolled DD14 steel. (a) The theoretical tensile material response in quasi-static conditions according to two different isotropic hardening laws is compared to experiments. (b) The engineering stress-strain curves of finite element simulations of the tensile test are confronted with the experimental curve.

To highlight this result, three simulations are compared to a tensile test performed on a $3 \mathrm{~mm}$ thick DD14 mild steel. One quarter of a 20x $80 \mathrm{~mm}$ tensile specimen has been meshed using linear reduced-integration hexahedra (C3D8R). According to a mesh sensitivity study, three elements through the half-thickness are sufficient. The engineering stress-strain curves corresponding to the three simulations are compared to the experimental results on Figure 2b. Difference between Voce and Swift-Voce quasi-static formulations is noticeable and well illustrates how the choice of hardening law for large strains can affect the accuracy of finite element simulations. As expected, due to its saturating behavior, the Voce hardening law predicts earlier necking than the Swift-Voce formulation. Considering now the difference between strain-rate sensitive and insensitive formulations with the Swift-Voce hardening law, predictions are similar when strain remains homogeneous and differ as soon as necking occurs. The well-known stabilizing effect of strain-rate sensitivity is well described: the increase of the flow stress with the strain rate allows delaying the necking by diffusing the deformation to adjacent areas.

Preliminary conclusions. In this part, the constitutive model has been implemented in the commercial finite element code Abaqus/Explicit using explicit time-integration scheme. On the basis of a simple finite element structure symbolized by a uniaxial tension specimen, numerical simulations have been confronted to experiments. Results demonstrated the importance of the choice of the hardening law at larger strains where the true stress-true strain experimental curve is no longer representative due to heterogeneous deformations. In the particular case of a quasi-static loading, effect of heterogeneous deformations within the structure showed the importance of taking into account the strain-rate sensitivity. The way to model such heterogeneous deformations in the structure by the constitutive law can greatly affect the accuracy of the finite element simulation. The proposed constitutive model is independent of hardening equations and can be coupled with any more advanced anisotropic yield surface. The proposed implemented model is therefore a suitable numerical tool to study and validate the choice of hardening laws beyond the scope of a true-stresstrue-strain curve. In the next part, the model is applied within a homogenization framework in order to further describe heterogeneous deformations at the phase scale and the effect of strain-path changes. 


\section{Homogenization approach at the phase scale}

To take into account explicitly the multi-phase microstructure of advanced high-strength steels developed in the last decades, constitutive laws can be derived within a homogenization framework. In this approach, each phase is described by a phenomenological elasto-visco-plastic model, and the homogenized macroscopic behavior is obtained using a scale-transition technique [10]. In this process, several features of the microstructure are lost through the modeling (texture, grain size, etc.) and are replaced by the usual phenomenological counterparts (yield function, hardening parameters). However, the volume fraction of the respective phases as well as their strength and hardening contrast explicitly enter the formulation, while the computational cost is almost the same as for a purely phenomenological model.

Scale transition rules. For the analysis reported in this section, the proposed model was coupled to simple scale-transition rules [11,12]. A virtual two-phase material was considered with a strength contrast similar to the one observed between ferrite and martensite in dual-phase steels (see Table 3). The elasticity response is taken to be identical in the two phases, and their hardening is described by Voce's law with different parameters. This simplified choice is made to emphasize the Bauschinger effect due to phase interaction, as revealed by the scale-transition rule. The macroscopic material response is represented in Figure 3 for the above dual-phase material when described by three material models corresponding to i) the Taylor-Lin (T-L) scale-transition rule, ii) the Kröner-Weng (K-W) scale-transition rule, and iii) a tabular representation of the T-L model under quasi-static monotonic tensile loading. The latter model thus corresponds to a purely isotropic hardening law, which is overlapped to the $\mathrm{T}-\mathrm{L}$ predictions along any quasi-static monotonic strain path and serves as a reference. Figure 3 clearly illustrates the Bauschinger effect due to the scaletransition rules; the three models predict significantly different stress evolutions after strain reversal. The respective accuracies of the scale-transition rules are beyond the scope of this investigation; the reader is referred to $[10,13]$ for the application in sheet forming simulation of more refined elasto-visco-plastic homogenization techniques [14] at the phase scale, combined with kinematic hardening in each of the phases.

Table 3. Material parameters for the virtual dual-phase steel.

\begin{tabular}{ccccccc}
\hline Phase & $\sigma_{0}[\mathrm{MPa}]$ & $C_{R}$ & $R_{\text {sat }}[\mathrm{MPa}]$ & $K^{*}[\mathrm{MPa}]$ & $\dot{\varepsilon}^{*}\left[\mathrm{~s}^{-1}\right]$ & $\begin{array}{c}\text { Volume } \\
\text { fraction }\end{array}$ \\
\hline Ferrite & 200 & 15 & 300 & 74 & 0.3 & 0.9 \\
\hline Martensite & 1600 & 10 & 50 & 74 & 0.3 & 0.1 \\
\hline
\end{tabular}




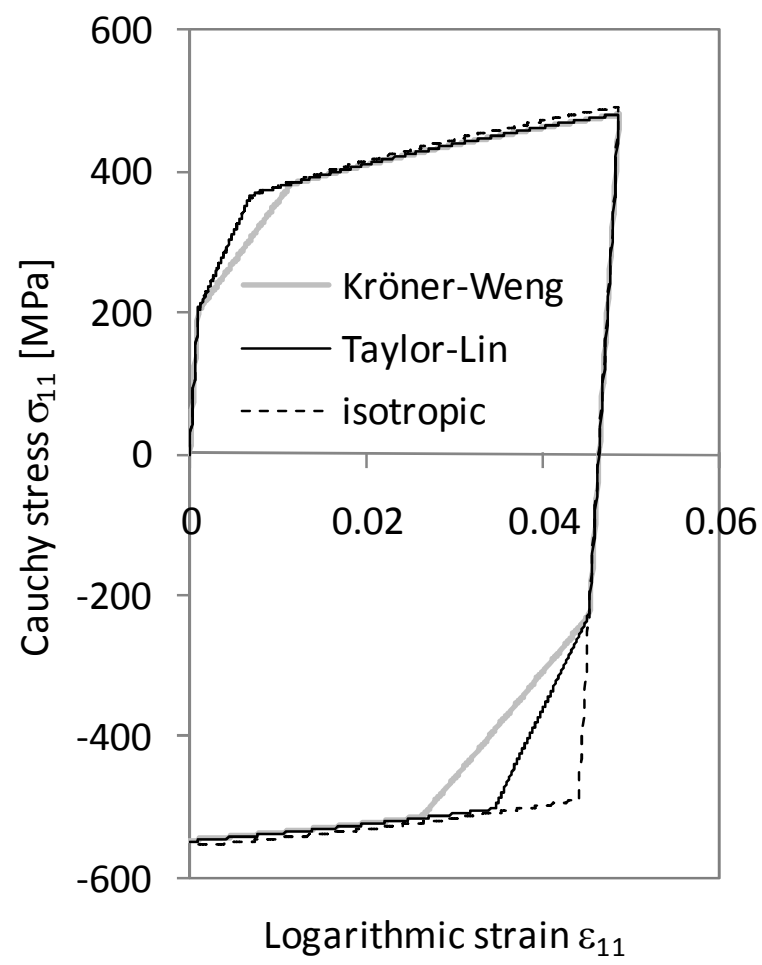

Figure 3. Kinematic hardening due to scale transition predicted by the two-phase models during a uniform quasi-static 5\% tensile loading followed by a reverse compression step.

Application to the 3D simulation of a two-step process. To mimic the strain-path changes that occur in multi-step stamping processes, a two-step process was simulated, which consists of a uniform $4 \%$ tensile loading of a rectangular sample, followed by V-bending. Such tensile predeformations are frequently used to explore the ability of constitutive models to predict the Bauschinger effect [15]. The geometry of the V-bending process is shown in Figure 4 together with the mesh of the sample. Due to symmetries, only one quarter of the sample is meshed.
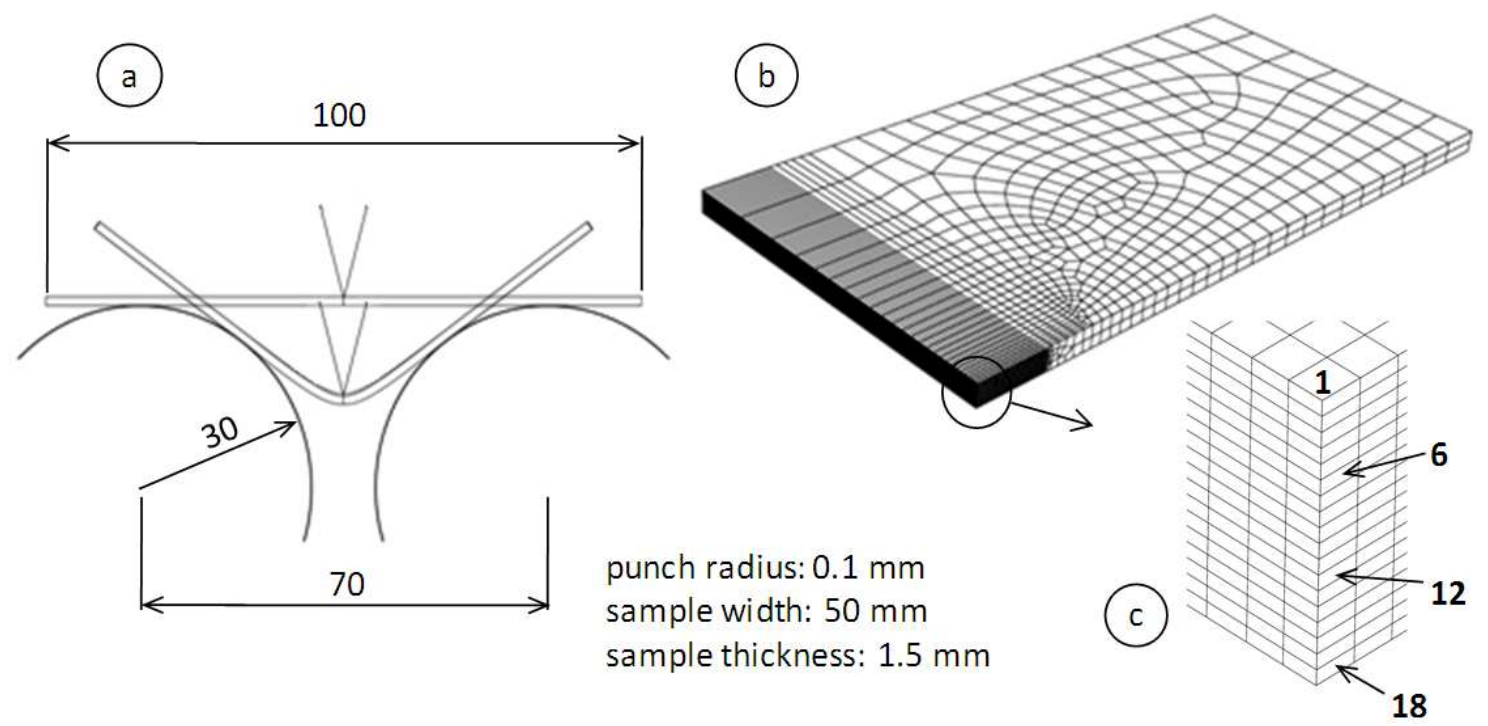

Figure 4. Finite element simulation of V-bending: a) geometry of the tools and sample at the beginning of the process and at 16-mm punch stroke; b) mesh of the sample; c) details of the mesh and number of through-thickness elements where the results were analyzed. 
The punch load evolution during the bending process is shown in Figure 5. The three models predict different punch loads; lower forces are observed for the models that exhibited larger Bauschinger effect in Figure 3. The maximum difference in punch load reaches $20 \%$ between the Kröner-Weng model and the isotropic model predictions.

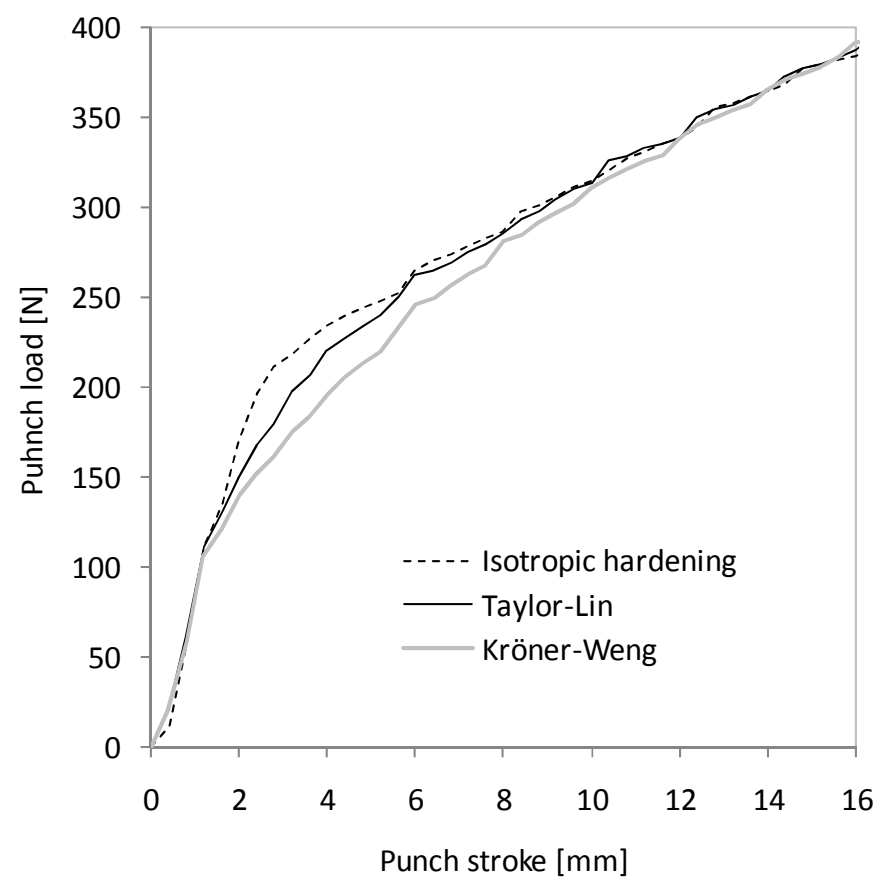

Figure 5. Finite element simulation of V-bending: punch load versus punch stroke.

This global result is corroborated by the stress-strain response recorded at the integration points of finite elements located through the thickness along a line close to its vertical symmetry plane (see Figure 4c). The material points located in the outer layers of the fold are reloaded in tension during bending, after the preliminary loading of tensile pre-strain, and the three models predict very similar responses at these points. However, the material points close to the punch are reloaded in compression and thus, the three models exhibit different degrees of Bauschinger effect in this region. If the bending process is continued, more complex strain-path changes may occur at some material points, as shown in Figure 6 because the "neutral surface" is moving towards the punch and material layers are accordingly switching from compression back to tension (in the direction of the sample length). This further illustrates the interest in accurate and physically based constitutive models for the finite element simulation of forming processes for the purpose of material design optimization.

Discussion. Implementing a homogenization scheme within a 3D finite element framework allows coupling the effect of the microstructure heterogeneities (volume fraction, grain size etc.) with heterogeneous stress and strain fields. The preliminary results of this paper demonstrated how the phase heterogeneity can impact the behavior of the whole structure when some elements experience some strain-path changes. This kinematic hardening, due to the mixing of two different phases, is classically neglected in a phenomenological approach. For the purpose of material design, coupling a homogenization approach within a $3 \mathrm{D}$ finite element environment is promising. Areas of a structure which experienced strain localization can be further analyzed with the help of natural outputs of a scale-transition model such as local strain and stress within the phases. Depending on the scale description, microstructure design (volume fraction of the phases, grain sizes etc.) can be optimized in order to improve the in-use properties. 

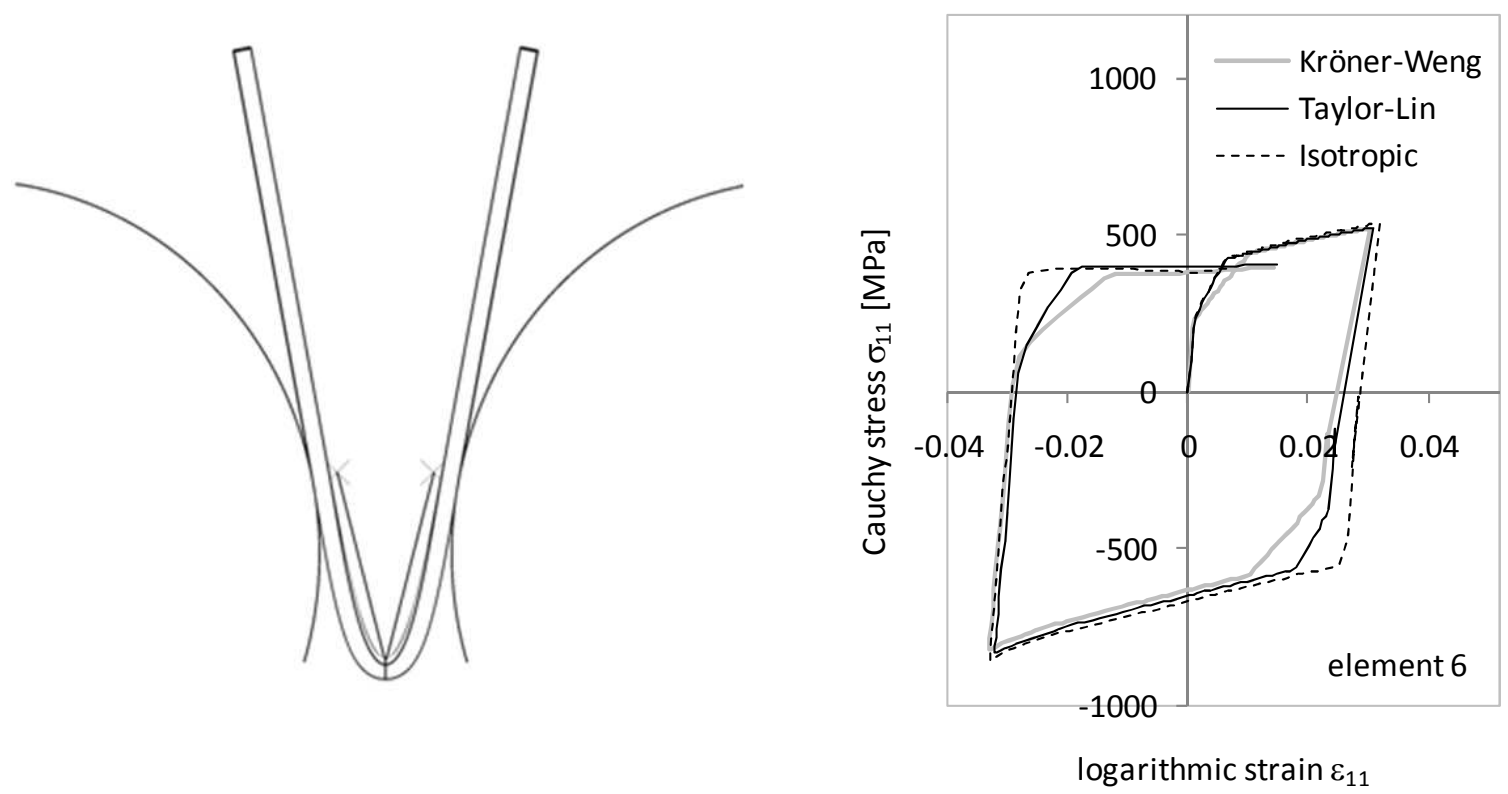

Figure 6. Bending predictions at a punch stroke of $40 \mathrm{~mm}$ : final geometry (left) and stress-strain curves at element 6 (right).

The main drawbacks of using a homogenization approach within a 3D finite element structure are essentially of two kinds. First, the choice of the transition rule is not straightforward (see Figure 6) and needs to be validated with experimental data. Secondly, the behavior of the material needs to be identified at the scale of description (phase scale in this example). Next step of this work is therefore to validate the approach with a large set of experiments.

\section{Conclusions}

The proposed constitutive elasto-visco-plastic model is a pragmatic alternative to existing models. Based on physical foundations, the proposed model requires a reduced number of fitting material parameters in comparison with other models from literature. Only two fitting material parameters are necessary to describe the strain-rate sensitivity. Temperature sensitivity can be taken into account by adding two additional material parameters. It is worth noting that the model is not restricted to any hardening equations or yield surface. Thanks to this flexibility, the approach represents a suitable tool to compare different hardening laws or isotropic/anisotropic yield surfaces. The model has been implemented in the commercial finite element code Abaqus/Explicit. Simple simulation of the post necking of a uniaxial tensile test experiment under quasi-static conditions illustrated how the strain-rate sensitivity and the hardening equations can impact the predictions of such simulations. Finally, the proposed approach has been applied in the framework of a homogenization approach at the phase scale. Predictions of a 3D two-step process simulation with a virtual dual-phase steel illustrated the benefits of coupling scale-transition techniques with 3D finite element simulations. Usually neglected, the effect of the kinematic hardening due to the mixing of the two phases has been underlined in this example. Identification of the material behavior at the phase scale is a great challenge that could significantly improve the material design for improved forming capabilities or in-use properties. 


\section{References}

[1] Allain, S., Bouaziz, O., Lemoine, X., 2009. A viscoplastic behavior law for ferritic steels at low homologous temperature. Revue de Métallurgie 106 (2), 80-89.

[2] Rauch, E.F., 1994. Relation between forest dislocations and stress in bcc metals. Key Eng. Mater. 97-98, 371-376.

[3] Pipard, J.M., Balan T., Abed-Meraim F., Lemoine X : submitted to International Journal of Solids and Structures (2012).

[4] Uenishi, A., Teodosiu, C., 2004. Constitutive modelling of the high strain rate behaviour of interstitial-free steel. Int. J. Plasticity 20, 915-936.

[5] Rusinek, A., Zaera, R., Klepaczko, J.R., 2007. Constitutive relations in 3-D for a wide range of strain rates and temperatures - Application to mild steels. Int. J. Solids Struct. 44, 5611-5634.

[6] Pipard, J.M., 2012. Modélisation du comportement élasto-viscoplastique des aciers multiphasés pour la simulation de leur mise en forme, $\mathrm{PhD}$ thesis, Arts et Métiers ParisTech, Metz, France.

[7] Lemoine, X., 2007. Behavior laws and their influences on numerical prediction. AIP Conf. Proc. 907, 269-274.

[8] Bui-Van, A., Allain, S., Lemoine, X., Bouaziz, O., 2009. An improved physically based behaviour law for ferritic steels and its application to crash modeling. Int. J. Mater. Form. 2, 527530.

[9] Lemoine, X., Sriram, S., Kergen, R., 2011. Flow curve determination at large plastic strain levels to accurately constitutive equations of AHSS in forming simulation. AIP Conf. Proc. 1353, 1417-1422.

[10] Gallée, S., Manach, P.Y., Thuillier, S., 2007. Mechanical behavior of a metastable austenitic stainless steel under simple and complex loading paths. Mater. Sci. Eng. A 466, 47-55.

[11] Taylor, G.I., 1938. Plastic strain in metals. J. Inst. Metals 62, 307-324.

[12] Weng, G.J., 1981. Self-consistent determination of time-dependent behavior of metals. ASME J. Appl. Mech. 48, 41-46.

[13] Gallée, S., Pilvin, P., 2010. Deep drawing simulation of a metastable austenitic stainless steel using a two-phase model. J. Mater. Proc. Technol. 210, 835-843.

[14] Pilvin, P., 1990. Approches multiéchelles pour la prévision du comportement anélastique des métaux. PhD thesis, Université Paris 6, Paris, France.

[15] Chung, K., Kuwabara, T., Verma, R.K., Park, T., Huh, H., Bae, G., 2011. Pre-strain effect on spring-back of 2-D Draw bending. In: Numisheet 2011 Benchmark Proceedings, September 2011, Seoul, Korea, 171-226. 